\title{
Experimental, numerical and analytical modelling of a newly developed rockfall protective cable-net structure
}

\author{
S. Dhakal ${ }^{1, *}$, N. P. Bhandary ${ }^{2}$, R. Yatabe ${ }^{2}$, and N. Kinoshita ${ }^{2}$ \\ ${ }^{1}$ Graduate School of Science and Engineering, Ehime University, Matsuyama, Japan \\ ${ }^{2}$ Department of Civil and Environmental Engineering, Ehime University, Matsuyama, Japan \\ *currently on study leave: Nepal Engineering College, Pokhara University, Bhaktapur, Nepal
}

Received: 1 August 2011 - Revised: 13 September 2011 - Accepted: 26 October 2011 - Published: 7 December 2011

\begin{abstract}
An innovative configuration of pocket-type rockfall protective cable-net structure, known as Long-span Pocket-type Rock-net (LPR), has been developed in Japan. The global performance of the proposed system was initially checked by the experimental (full-scale) modelling. Given the various limitations of the physical experiments, particularly for the parametric study to have a detailed understanding of the newly developed system, a reliable and simplified method of numerical modelling is felt necessary. Again, given the sophistication involved with the method of numerical simulation, a yet simplified modelling approach may prove more effective. On top of this background, this paper presents a three-tier modelling of a design of LPR. After physical modelling, which has revealed that the displacement response may be taken more vital for LPR performance, Finite Element based numerical modelling is presented. The programme LS-DYNA is used and the models are calibrated and verified with the element- and structure-level experiments. Finally, a simple analytical modelling consisting of the equivalently linear and elastic, lumped-mass, singledegree-of-freedom system, capable of predicting the global displacement response, is proposed based on the basic principles of conservation of linear momentum and energy. The model is back-calculated and modified from the analyses of the verified numerical model.
\end{abstract}

\section{Introduction}

Rockfall is an important geo-hazard of mountainous terrains around the globe and is gaining increased attention and recognition due primarily to the severe accidents and mortalities in mountain-highways and -railways, and even buildings,

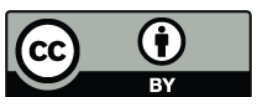

Correspondence to: S. Dhakal

(shankerd@nec.edu.np) for instance, in the Alps. Despite being a small-volume hazard, it has been covering a wide range of technical and scientific literatures. Rockfall analysis/simulation (e.g. Giani, 1992; Evans and Hungr, 1993; Azzoni et al., 1995; Giani et al., 2004; Ushiro, 2006) characterises the various possible block trajectories and yields the information, such as runout lengths, bounce heights, impact velocities and energies. Several computer programmes have already been developed and tested to simulate rockfall either by a lumped mass or a rigid body, 2-D or 3-D approach (Guzzetti et al., 2002) with or without considering the vegetation effects explicitly (e.g. Dorren and Berger, 2005; Masuya et al., 2009). A good deal of literature is also available which analyses the risk from rockfall hazard (e.g. Bunce et al., 1997; Crosta and Agliardi, 2003; Guzzeti et al., 2003; Peila and Guardini, 2008). Rockfall simulation and/or the risk analysis ultimately become useful for the land-use planning (a guidance on landslide susceptibility, hazard and risk zoning for land-use planning can be found in Fell et al., 2008a, b), and for the selection, location and dimensioning of the passive mitigation (protective) structures when the land-use planning cannot avoid the hazard area or when the existing assets are to be preserved (Vogel et al., 2009). In fact, active mitigation (preventive) measures, such as rock-bolting, shotcreting, scaling, gluing, wire-meshing/drapery meshing, blasting, etc. may help, but they are not easy to execute and their effectiveness is difficult to quantify by means of stability analyses or visual observations (Descoeudres et al., 1999), thereby emphasizing the research expedition on protective measures.

Amongst the various rockfall protective measures, a costenergy trade-off analysis (Yoshida, 1999) reveals that flexible barriers/cable-net structures may be the most attractive alternative for low-to-medium impact energy rockfall hazard scenarios; say below $500 \mathrm{~kJ}$. For instance, Japan most often witnesses such a scenario (Muraishi et al., 2005). The past major studies on the global structural performance of rockfall protective cable-net barriers or fences, either by

Published by Copernicus Publications on behalf of the European Geosciences Union. 
Table 1. The chronological list of the full-scale tests of various LPRs in the past verification and demonstration campaign. The highlighted case of the $15 \mathrm{~m}$ span, $150 \mathrm{~kJ}$ designated impact energy capacity is taken as a reference case LPR in the present study.

\begin{tabular}{lllllll}
\hline Date & $\begin{array}{l}\text { UFDs } \\
\text { integrated? }\end{array}$ & $\begin{array}{l}\text { Span } \\
(\mathrm{m})\end{array}$ & $\begin{array}{l}\text { Height } \\
(\mathrm{m})\end{array}$ & $\begin{array}{l}\text { Test-block } \\
\text { mass (ton) }\end{array}$ & $\begin{array}{l}\text { Incident } \\
\text { velocity }\left(\mathrm{m} \mathrm{s}^{-1}\right)\end{array}$ & $\begin{array}{l}\text { Energy } \\
(\mathrm{kJ})\end{array}$ \\
\hline 2007.12 .20 & No & 15 & 10 & 0.5 & 16.73 & 70 \\
2008.12 .20 & No & 15 & 10 & 0.5 & 16.73 & 70 \\
2008.4 .16 & Yes & 15 & 10 & 0.7 & 16.90 & 100 \\
2008.4 .16 & Yes & 15 & 10 & 0.7 & 16.90 & 100 \\
2008.5 .27 & Yes & 15 & 10 & 0.7 & 16.90 & 100 \\
$\mathbf{2 0 0 8 . 5 . 2 7}$ & Yes & $\mathbf{1 5}$ & $\mathbf{1 0}$ & $\mathbf{1 . 0}$ & $\mathbf{1 7 . 3 3}$ & $\mathbf{1 5 0}$ \\
2008.10 .10 & Yes & 30 & 10 & 2.0 & 19.52 & 380 \\
2008.10 .29 & Yes & 30 & 10 & 2.0 & 19.52 & 380 \\
2008.11 .4 & Yes & 30 & 10 & 2.1 & 19.52 & 400 \\
2008.12 .8 & Yes & 30 & 10 & 2.1 & 19.52 & 400 \\
\hline
\end{tabular}

full-scale physical modelling or numerical modelling, can be traced from Smith and Duffy (1990), Peila et al. (1998), Gerber (2001), Nicot et al. (2001), Cazzani et al. (2002), Grassl et al. (2002), Volkwein (2004, 2005), Muhunthan et al. (2005), Muraishi et al. (2005), Maegawa (2006), Sasiharan et al. (2006), Castro-Fresno et al. (2008), EOTA (2008), Peila and Ronco (2009), and Gottardi and Govoni (2010). Over the evolution of time, these systems have been subjected to changes in their configuration and/or composition to enhance their performance and/or capacity, offsetting the disadvantages or limitations of the prevailing designs. Introduction of highly flexible barriers of capacity as high as $5000 \mathrm{~kJ}$ in Europe such as in Switzerland, Italy and France, and hybrid barrier-drape system/attenuator (e.g. Badger et al., 2008) and "pocket-type rock-net" (Japan Road Association, 2000; Tajima et al., 2009), respectively, in the USA and Japan are among a few notable developments. The research towards better understanding and standardization of the drapery meshes (or wire-meshes or rock covering wire nets) (e.g. Yoshida, 1999; Muhunthan et al., 2005; Bertolo et al., 2009) are also continuing in parallel to the development of new flexible barrier (cable-net) systems.

Recently in Japan, a new configuration of pocket-type rockfall protective cable-net barrier has been developed and named "Long-span Pocket-type Rock-net" (Kinoshita, 2009; Dhakal et al., 2011a), hereafter referred to as LPR. The structure is proposed for its effective application in lowto-medium rockfall hazard sites with limited clearance between the road carriageway and hill-slope. For the time being, through a limited number of test-verifications (Table 1), the LPRs of a span up to $30 \mathrm{~m}$ and the corresponding design impact energy capacity of $400 \mathrm{~kJ}$ have been developed. Figure 1 portrays the steel structure of a typical LPR. It essentially consists of wire-net (mesh), reinforcing and connecting horizontal-, vertical- and sag-cables (wireropes) and additional energy dissipating brake devices (precisely, the U-bolt-type Friction-brake energy dissipating Devices: UFDs) as the main impact resilient components. The overall cable-net system is supported over the slanted posts (standard rolled steel sections) at either end, and all the horizontal and post-supporting guy-cables are firmly anchored to the ground (slope).

Before the introduction of LPR, either short-span (3 or $5 \mathrm{~m}$ ) pocket-type rock-net or rock-sheds (reinforced concrete galleries) were prevalent in the described sites. The former not only had lower capacity (thereby requiring installation in cascade uphill) and incurred larger cost for more materials as well as installation, but also performed weakly by having their posts repeatedly damaged by the direct impact of the falling rock-boulder. The latter was not only difficult to construct and having a very high dead-load, but was an expensive alternative, especially because they have a high-tovery-high capacity range which is never utilised in the lowto-medium rockfall hazard sites. With the advent of LPR system, the disadvantages of the prevailing solutions have been overcome and in either case, LPR has ecological benefits as well. The system was first piloted in real field at various locations of Kurei-Suzaki Line road, along the Pacific Ocean, in Kochi Prefecture of Japan, and the subsequent performance has been found satisfactory. The LPRs are now finding an increased application within Japan and imilar systems are expected to be developed in future in other parts of the world too. In fact, assuming the construction materials are fairly available, rockfall protective earthen embankments (or geo-cells) widely developed, tested and used in various parts of the world such as in France, Italy and Japan (e.g. Peila, 2011) can be as effective and economical as flexible barriers even in the low-to-medium rockfall hazard sites. However, they generally require a larger space and the design like LPR can be a good alternative in such a constraint. In the USA (e.g. Arndt et al., 2009; Badger et al., 2011; Eliassen, 2011), and later in Switzerland (e.g. Boetticher et al., 2011), and probably in other parts of the world too, the authors' web-survey has found that a similar configuration of a rockfall protective cable-net structure named "Hybrid Drapery" or "Hybrid Rockfall Barrier/Drape System" has been widely 

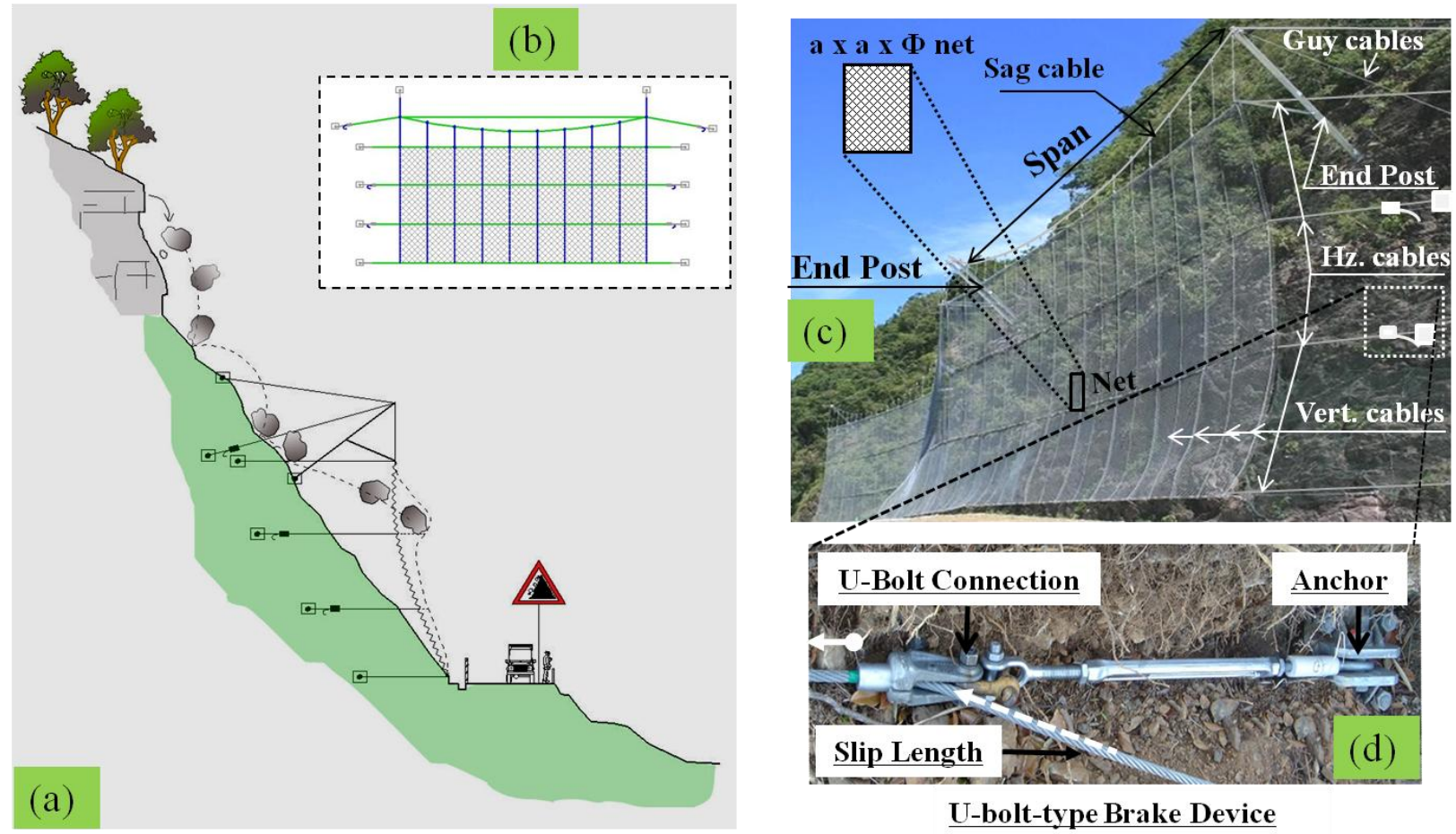

Fig. 1. LPR structure. (a): schematic sectional side view of a typical LPR structure intercepting the falling rock-boulder in a mountain-road. (b): front elevation of the typical LPR. (c): LPR structural components illustrated over a picture taken from the real field installation. (d): a UFD installed in the LPR; shown schematically in (c).

developed, tested and used independently. However, they have a different composition, different reinforcing and supporting system for wire-net, possibly different brake devices and arrangements, etc. Furthermore, the mechanism of interception is also different as there is as such no "tail" like construction in LPR system and the whole energy of the falling rock-block is required to be intercepted by the barrier itself like in a "fence". Therefore, the available database for Hybrid Drapery may not be useful in the study of the newly developed LPR structure and a separate research is necessary.

The global performance of the proposed LPR structural system was evaluated by the full-scale physical modelling. Given the various limitations of the full-scale modelling (e.g. Cazzani et al., 2002; Volkwein, 2005; Miranda et al., 2011), particularly for the parametric study necessary to have the detailed understanding and characterisation of the newly developed system, the method of numerical modelling is felt to be necessary. Again, by virtue of the sophistication involved in the numerical modelling, it may not be always practicable and/or sufficient as well, for instance, with regard to the requirements of own sanity check by the design engineers (Lam et al., 2010). Thus, a simplified modelling approach may yet prove more effective. Encouraged by the mentioned need, a three-tier modelling is discussed in this work. In fact, with the increasing applications of this structure inside Japan and having that similar structure is likely to be developed outside as well; there is an important step in LPR research next door - the preparation of the design code of practice for the structure. Additionally, having newly conceived only a limited number of geometries and configurations that have so far been test-verified, there could have been a number of opportunities left to optimize or improve the proposed design. Furthermore, with the easily replicable and verified numerical and/or analytical modelling described in the present work, investigation on various confusions and gaps revealed from the state-of-the-art literatures, for example, on the characterisation of rockfall impact loading onto a protective cable-net system (Cazzani et al., 2002; Cantarelli et al., 2008; Volkwein et al., 2009) or possibly in any generic system (Yang et al., 2011), may be conveniently accomplished.

\section{Full-scale modelling (FM)}

For the sake of design verifications and in some cases also for the sake of public demonstration of the newly developed structure, almost a dozen of tests (Table 1) were conducted during the past test campaign. The campaign was led by a few local consultants of Shikoku Island of Japan in collaboration with Ehime University. However, for the time being, only one model is discussed throughout this paper. The successfully tested and instrumented design of a $15 \mathrm{~m}$ span and of designated design impact energy resistant capacity of $150 \mathrm{~kJ}$ is taken as a reference case. The reference case LPR 


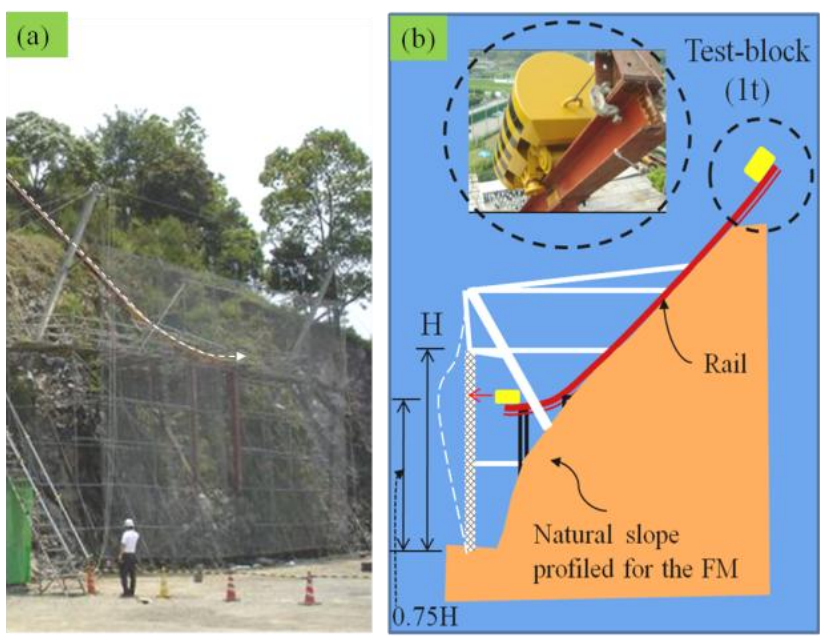

Fig. 2. The FM set up in the LPR test campaign. (a): a picture taken from the FM test site in Kochi, Japan (2008.5.27). (b): sectional side view illustrating the test set-up. Picture of cylindrical block used in the test is also shown. This block is released from a predefined height at the top of the rail, and traversing along the ideally frictionless rail, it hits the net at the specified point $(0.75 \mathrm{H}$ in the mid-span).

is highlighted in Table 1 and may be found referred to as RLPR hereafter.

\subsection{Test set up and the procedure}

Figure 2 illustrates the FM set up and situation of the R-LPR. A cylindrical reinforced concrete block of a certain geometry (length to diameter ratio of 2) was assumed as an idealized rock-block. The block weighing 1 ton was released from a certain height and guided over the specially manufactured rail positioned onto a profiled hill-slope so that it hit the wire-net with a predetermined velocity of $17.33 \mathrm{~m} \mathrm{~s}^{-1}$ (kinetic energy of $150 \mathrm{~kJ}$ ) horizontally (i.e., perpendicular to the net) at the specified impact point (Japan Road Association, 2000) located at mid-span, 3/4th height of wire-net equalling to $7.5 \mathrm{~m}$. In fact, the possibility of other possible worst scenarios of idealized rock-block shapes or sizes or impact points may be questioned here, but that exploration is beyond the scope of this paper, but may be found briefly discussed in Dhakal et al. (2011b).

The set up was installed with the load-cells (strain gauges) in the cables in front of anchors to measure the tension developed in the cables or dissipators, while the motion and displacement-related measurements were monitored and framed by the high-speed video cameras; the magnitudes having calculated later on by the image processing. Figure 3 illustrates some important aspects as was observed and instrumented in the FM.

\subsection{Test results}

The cable tension and the out-of-plane displacement have been considered to be the most important response quantities to check the force and displacement performance criteria, while the information on slip-displacements of the brake elements (UFDs) may be necessary to evaluate their efficiency. In fact, the wire-net (wire-mesh) of the structure is purposefully made strong, and as witnessed in the past test campaign or in the various rockfall case histories afterwards, it is assumed that there shall be hardly any problem of perforation or cutting effects of net by rock-boulders. Thus, in the FM (or the corresponding NM detailed in Sect. 3), only the aforementioned three response quantities have been described explicitly by the authors. Furthermore, because LPR is to be installed just beside the road with limited space between the hill-slope and the carriageway, displacement based performance criteria (serviceability criteria) may be more vital, given that the stresses are within safe limits. This may be a typical consideration in LPR unlike other types of rockfall protective flexible barriers or fences devised in Europe or elsewhere.

The maximum tension was recorded in the middle horizontal cable (Kinoshita, 2009), marked by a circle at location $\mathrm{M}$ in Fig. 3a. The time history record of the respective force is shown in Fig. 3c, where it reaches up to $94 \mathrm{kN}$. Correspondingly, the maximum slip-displacement was also measured at the same location and it is reported to be $134 \mathrm{~mm}$ (Kinoshita, 2009). The study of images captured by the video cameras reveals that the global displacement response (maximum out-of-plane displacement of wire-net) was $3.5 \mathrm{~m}$ (Kinoshita, 2009). For the sake of visual impression, a sequence of images at the interval of $0.1 \mathrm{~s}$ is presented in Fig. 3e, the last image showing the maximum deformed stage. The fact that the observed value of $94 \mathrm{kN}$ tension $\left(\right.$ stress $=94 \mathrm{kN} / 163 \mathrm{~mm}^{2}=577 \mathrm{MPa}$ ) in the cable having the yield stress limit of $990 \mathrm{MPa}$ or the breaking stress limit of $1316.7 \mathrm{MPa}$ may conclude that the existing impact energy resistant capacity designation of the structure is conservative. Furthermore, the use of the available yet higher strength cables, without very significant difference in costs, may enhance the band of the large reserve of energy absorbing capacity. Moreover, having said that the wire-net is purposefully made very strong, no damage or fracture was observed. Owing to the sufficiently safer stress state in the cable as well, the displacement-based performance criteria may be emphasized in the analysis and design of an LPR structure. The measured displacement response, i.e., the wire-net's outof-plane displacement of magnitude $3.5 \mathrm{~m}$, in general, may be assumed to be serviceable and safer with respect to the damage the structure may cause to the road-traffic during its stopping of the falling rock-boulder. However, it really depends on the availability of the road width beside the hillslope based on the local topography. 

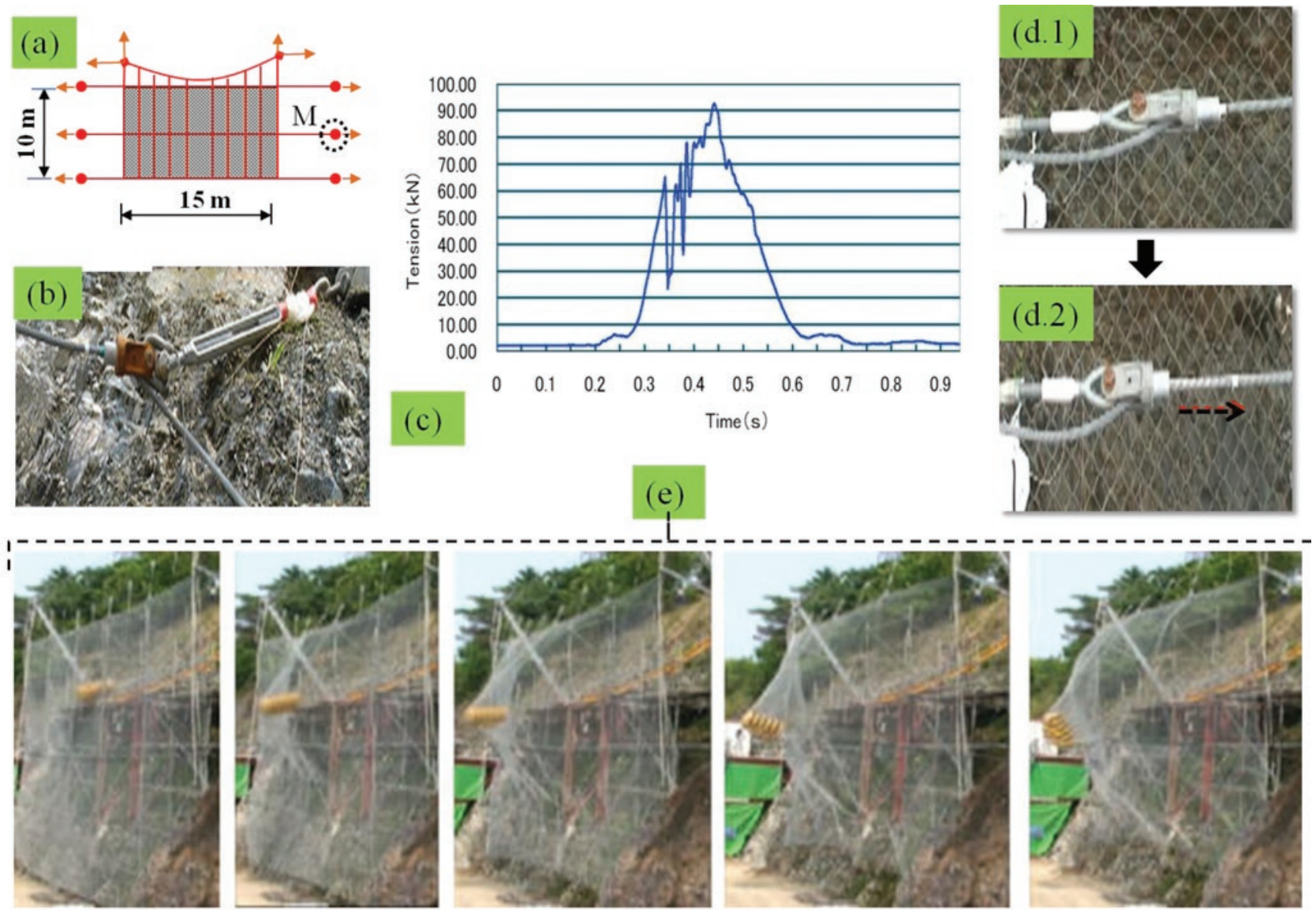

Fig. 3. Observation and instrumentation in the FM of R-LPR. (a): simple schematic front elevation of R-LPR, with the location of maximum cable tension or corresponding UFD slip-length shown by circle at M. (b): load cell or strain gauge installed just before anchor, which sends the tension developed in the cable near UFD to the data logger computer system (not shown). (c): time history of maximum cable tension instrumented by load cell at M. (d1) a UFD before slip. (d2) the same UFD after slip. (e): sequence of images of LPR deformation shown at an interval of $0.10 \mathrm{~s}$, captured by the high-speed video cameras (not shown); the respective out-of-plane deformation was recorded approximately to evolve up to $3.5 \mathrm{~m}$ through $0.0 \mathrm{~m}, 0.5 \mathrm{~m}, 1.5 \mathrm{~m}$ and $2.5 \mathrm{~m}$.

\section{Numerical modelling (NM)}

The LPR structure may be one of the ideal situations to apply the numerical method of Finite Element (FE) modelling and simulation. The straight-forward simplification in structural modelling and characterisation of this structure to study by simplified analytical formulae is virtually impossible owing to the fact that the structure involves a complex composition and interaction between its various impact resilient components, mainly the cable, the wire-net and the dissipators. This necessitates the employment of a numerical method as capable as ordinary FEM (e.g. Reddy, 2004; Dhakal et al., 2011c). Moreover, the continuum method of FEM should be sufficient as well, due to the very fact the wire-net being purposefully made very strong, either cutting or perforation has not been evident. This may justify that a particle method such as the Smoothed Particle Hydrodynamics, SPH (Fukazawa et al., 2010) is not required to be considered in the study.
The available FE-based programme, LS-DYNA, having the capabilities to conduct the rigorous, dynamic and nonlinear (both material and geometric) analysis of a structure subjected to transient vibrations (Hallquist, 2006), is used. However, foreseeing that the developed numerical model shall have to be utilized in future toward conducting a large volume of parametric analyses to address various identified problems such as the impact loading characterisation, the identification of effective and efficient configurations and the development of the sought design charts and design guideline of LPR structures (all beyond the scope of the present paper, mainly for brevity), a simplified and equivalent modelling approach was followed wherever acceptable, without going into interface- or micro-level detailing. The acceptable approximations in the numerical modelling of LPR includes the generalization or simplification in the orientations of supporting system, the equivalent shell modelling of wirenet mesh and finally the equivalent truss modelling of the dissipators (UFDs). 


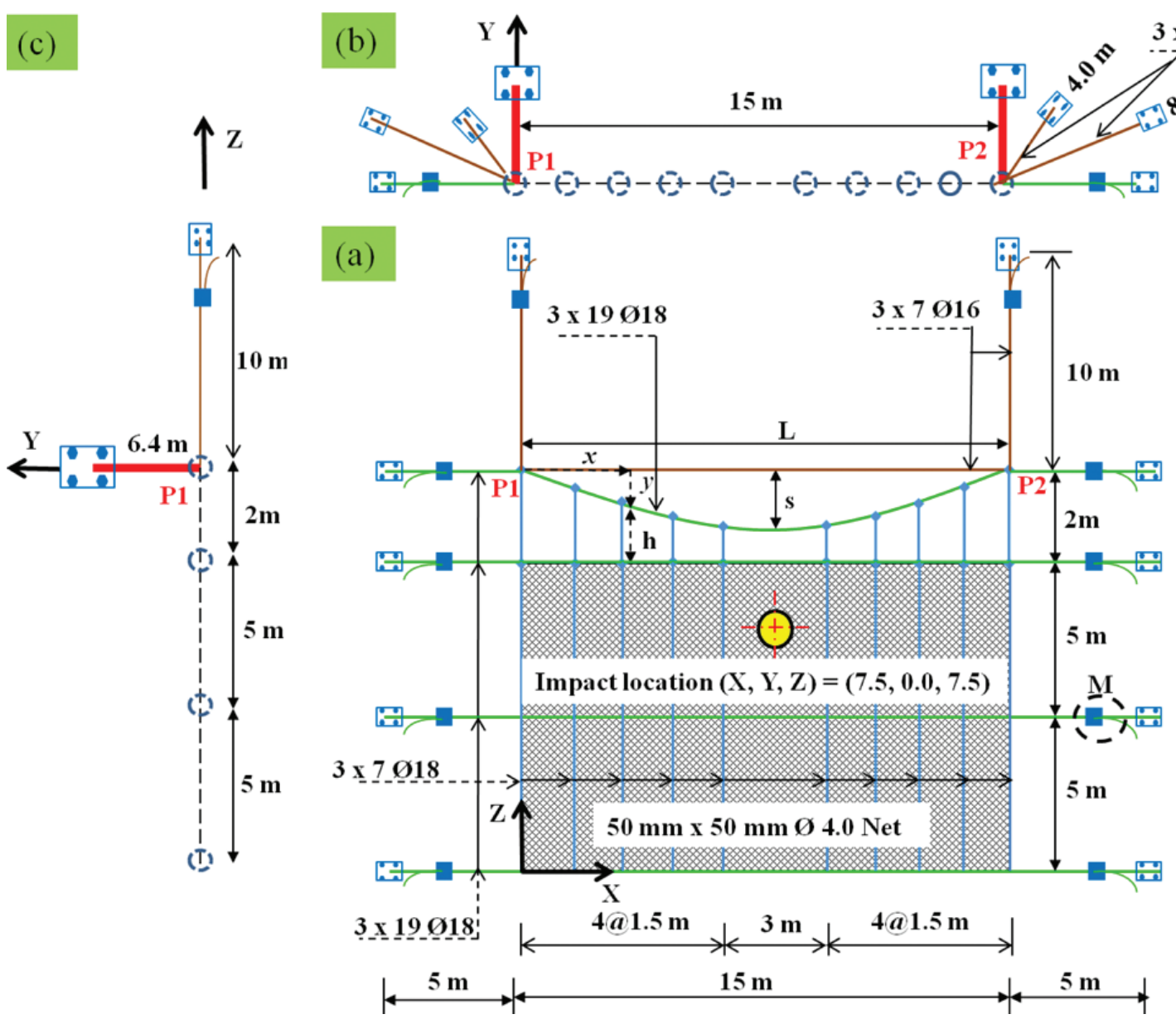

Fig. 4. Geometry and composition of R-LPR model with acceptable approximations. (a): front elevation showing the local coordinates axes $(\mathrm{x}, \mathrm{y})$ of parabolic sag-cable and global axes $(\mathrm{X}, \mathrm{Z})$ of system geometry. (b): top view on X-Y plane. (c): side elevation on Y-Z plane viewed from left (negative $\mathrm{X}$ axis).

\subsection{Model geometry and composition}

In fact, the orientations of posts and guy-like supporting cables outward from the posts toward the anchors vary from case to case which may be observed both in the various prototypes considered in the past test campaign as well as the real constructions in the field implementation afterwards, mainly attributed to the existing topography of the hill-slope. Moreover, it has been understood that these members primarily act as the restraints to the main cable-net-dissipator structural system - the limelight of the study - and that they are relatively less stressed as well. Also, again based on the past observations or assumption of a careful foundation soil investigation or necessary strengthening, the authors assume that the bearing capacity of each anchor foundation is well above the highest stresses by rockfall impact. Therefore, any generalized orientation of theirs should be acceptable unless, hypothetically, we are to focus our study on the supporting members themselves. This assumption should not have a considerable effect in the main impact resilient structural system. In the present attempt to numerically model the R-LPR, the authors assumed the corresponding supporting members lay only on the horizontal and vertical planes. The approximated configuration, together with the details of the overall structural geometry as well as the composition of the structure is shown in Fig. 4.

The initial geometry (catenary shape) of the sag cable has been approximated by a parabolic curve due to having a lower value of sag (say, less than or equal to one tenth of the span as considered in the design and observed in the field). With the origin of coordinates of the parabola being at either of the end-posts (also shown in Fig. 4), the y-coordinates of the sag-cable parabola having span $L$ and design sag $s$ are given by Eq. (1).

$\mathrm{y}=\frac{4 s \mathrm{x}(L-\mathrm{x})}{L^{2}}$

The lengths of hangers (or equivalently the lengths of the portion of vertical cables between sag cable and wire-net's 

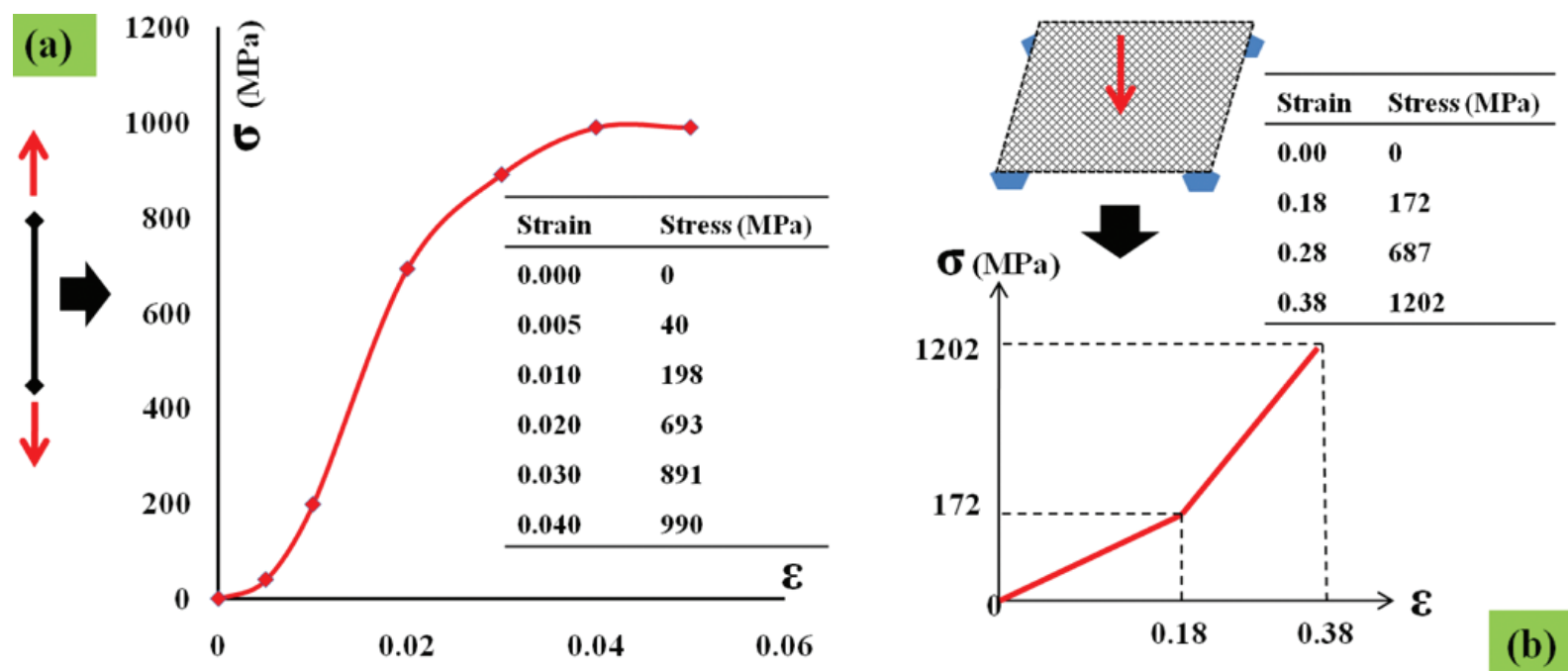

Fig. 5. Nonlinear stress-strain curves of cable (a) and shell equivalent wire-net (b).

top edge) may be obtained by subtracting the y-ordinates (y) of the parabola from $2 \mathrm{~m}$. Thus, the lengths of the hangers (h) from left to right, corresponding to the $\mathrm{x}$-coordinates $(\mathrm{x})$ : $0.0 \mathrm{~m}, 1.5 \mathrm{~m}, 3.0 \mathrm{~m}, 4.5 \mathrm{~m}, 6.0 \mathrm{~m}, 9 \mathrm{~m}, 10.5 \mathrm{~m}, 12 \mathrm{~m}, 13.5 \mathrm{~m}$ and $15.0 \mathrm{~m}$, come out to be respectively $2.00 \mathrm{~m}, 1.52 \mathrm{~m}$, $1.04 \mathrm{~m}, 0.80 \mathrm{~m}, 0.56 \mathrm{~m}, 0.56 \mathrm{~m}, 0.80 \mathrm{~m}, 1.04 \mathrm{~m}, 1.52 \mathrm{~m}$ and $2.00 \mathrm{~m}$. The larger segment of $3 \mathrm{~m}$ in the middle portion was meant for the direct impact of the test block onto the wirenet for worst impact scenario for local damage/perforation, if any.

\subsection{Choice of finite elements, material models and their calibration}

The wire-net (mesh) was modelled equivalently by Belytschko-Tsay shell elements with Fabric material model (MAT_034), as a computationally efficient alternative to Hughes-Liu shell elements (Hallquist, 2006). The choice of Fabric material model was encouraged from the fact that, "in addition to being a constitutive model, this model also invokes a special membrane element formulation which is more suited to the deformation experienced by fabrics under large deformation" (LSTC, 2007). The nonlinear stressstrain curve was obtained accordingly via a slab-like panel test of the net (Fig. 5b). The cables were modelled by Discrete Beam Cable elements and their nonlinear material model (MAT_071) was calibrated with the piecewise linear stress-strain curve data obtained from the uniaxial tensile test (Fig. 5a). The posts were modelled by Discrete Beam element with the elastic-linearly plastic, isotropic hardening material model having the properties of the ordinary steel (yield stress $=300 \mathrm{MPa}$ and hardening parameter $\left.\left(E_{t} / E\right)=0.1\right)$. The corresponding sectional properties (such as cross-sectional area, moments of inertia, etc.) were assigned subsequently as defined in the programme's user manual (LSTC, 2007). The density of any steel member is considered the same and a constant value of $7840 \mathrm{~kg} \mathrm{~m}^{-3}$. The cross-sectional areas of the various cables used in the R-LPR are $163 \mathrm{~mm}^{2}, 140 \mathrm{~mm}^{2}$ and $125 \mathrm{~mm}^{2}$, respectively, for the $(7 \times 19 \times 18 \Phi),(3 \times 7 \times 18 \Phi)$ and $(3 \times 7 \times 16 \Phi)$ cables. The weight per unit area and the thickness of the equivalent shells of the wire-net are, respectively, $4.6 \mathrm{~kg} \mathrm{~m}^{-2}$ and $0.587 \mathrm{~mm}$.

The UFD were modelled equivalently by Discrete Beam Truss element of a certain length and area with such a constitutive model that the permanent elongation of the truss element equivalently corresponds to the slippage (slipdisplacement) in reality. These devices integrated into LPR structure were in fact developed and tested a few years earlier for the purpose of integrating into another type of rockfall protective rock-net. Besafe (2006) had tested their dynamic performance in isolation under the falling weight impact test (FWT). For a quick reference, a schematic of the test with one typical time history of cable tension measured by load cell is given in Fig. 6. The average limiting tension (sliptension) of the UFDs presently used in the R-LPR was reported to be $50 \mathrm{kN}$ with the corresponding slip-displacement of $50 \mathrm{~cm}$. The measurements were precise with an interval of approximately $\pm 5 \mathrm{kN}$ and $\pm 5 \mathrm{~cm}$. Purposefully, the UFDs were designed to slip at a tension well below the ultimate tension of cable and, hence, allowing certain tension to rise even after the slip while braking. This may be observed from Fig. $6 \mathrm{~b}$ itself, where there is rise in tension in the cable as high as approximately $70 \mathrm{kN}$. Or, simply the fact that the maximum tension developed in the cable integrated with UFD in the FM described in Sect. $2(94 \mathrm{kN})$ is appreciably greater than the designated slip-tension. Therefore, an elasto-plastic hardening model is deemed necessary for the UFD-equivalent truss elements. The authors assume 


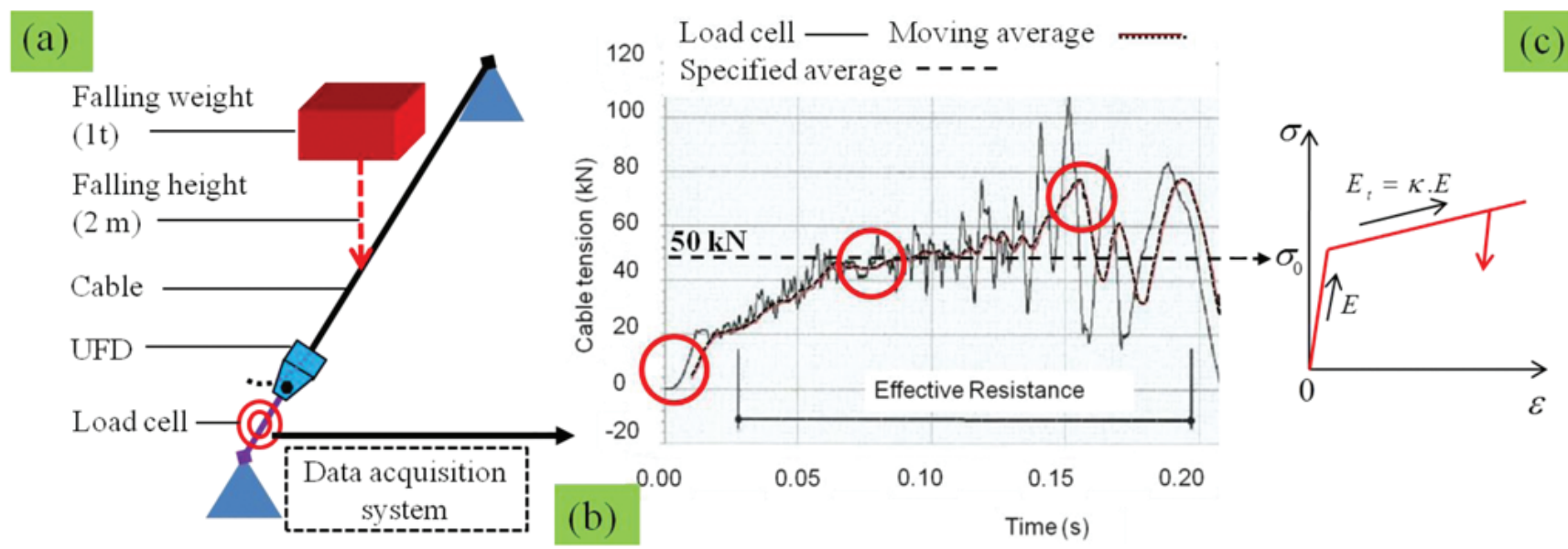

Fig. 6. Constitutive modelling of UFD. (a): the scheme of FWT set up for an isolated UFD conducted by Besafe (2006). (b): the recorded time history of cable tension together with the 200-moving-point average curve and specified average slip-tension value shown. Also shown are the milestones in the history shown by circles. (c): the assumed constitutive model for UFD-equivalent truss elements in the NM (FE modelling).

a linear hardening material model in the present simulation, precisely the Plastic Kinematic (MAT_003) model available in LS-DYNA. The model is shown in Fig. 6c.

As per the calibration of the UFD-equivalent Plastic Kinematic constitutive model, another assumption was made. In fact, the gradients of force-displacement response of UFD after slip in the FM of LPR (Some $94 \mathrm{kN}$ tension after the slip-displacement of $134 \mathrm{~mm}$ ) and in the FWT of the isolated specimen (Some $70 \mathrm{kN}$ maximum averaged tension after the slip-displacement of $500 \mathrm{~mm}$ ) are different. A separate analysis on this together with other various aspects of the dissipators to be integrated into LPR structures may be found in a companion contribution by the authors in the future. Currently, for the purposes of simulation, the observation made in the FM was used to calibrate the hardening parameter $(\kappa)$ or the degraded Young's modulus $\left(E_{t}\right)$ with the yield stress $\left(\sigma_{0}\right)$ corresponding to the specified slip-tension of $50 \mathrm{kN}$. Considering the length of $0.5 \mathrm{~m}$ (without explicitly modelling the connecting steel between UFD and the anchor) and an arbitrary cross-sectional area of $1000 \mathrm{~mm}^{2}$, the yield stress and hardening parameter of the UFD-equivalent plastic hardening model come out to be, respectively, $50 \mathrm{MPa}$ and 0.001 (rounded off) - calculation shown below.

$\sigma_{0}=\frac{T_{0}}{A}=\frac{50 \times 10^{3}}{1000}=50 \mathrm{MPa}$

$E_{t}=\kappa \times E \Rightarrow$

$\kappa=\left(\frac{(94-50) \times 10^{3} / 1000}{134 / 500}\right) / 2.10 \times 10^{11} \approx 0.001$

Here, $E$ has been taken equal to $210 \mathrm{GPa}$ - that of a steel bar connector between the U-bolt head and anchor in reality. In fact, until slip occurs, there is virtually no existence of UFD role and it acts simply like the bar connector between the cable and anchor.

All anchor nodes including the hinged bases of posts were restrained against translation in all directions.

\subsection{Numerical analysis}

To incorporate the effects of initial sag or pretension primarily in the sag-cable, the uniformly distributed vertical load composing of its own weight added with the dead load - imposed by the net mesh and the reinforcing vertical cables including hangers - was approximately calculated by Eqs. (4) and (5), and the tension in the sag-cable of the defined geometry was computed by equilibrium equations, Eqs. (6) to (8), resulting in an approximate value of $11 \mathrm{kN}$ at any point between the post-supports. This was then assigned as $F_{0}$ in the Discrete Beam Cable material model inbuilt into LS-DYNA (LSTC, 2007). In fact, the maximum inclination of the cablenet configuration of R-LPR with vertical in the FM or the corresponding NM, or in the real-field installation of a typical LPR, stays negligibly small to zero. Therefore, the assumption of constant pretension force in the sag-cable $\left(F_{0}\right)$ is pretty acceptable.

Total dead load on the sag-cable:

$W=(w \times A)_{\text {wire-net }}+\sum_{\text {vert.cables }}(w \times l)$

where, $w=$ intensity of load (per unit length for verticalcables $=1.10 \mathrm{~kg} \mathrm{~m}^{-1}$ and sag-cables $=1.28 \mathrm{~kg} \mathrm{~m}^{-1}$, and per unit area for wire-net $=4.6 \mathrm{~kg} \mathrm{~m}^{-2}$ ); $l=$ length of vertical cables including hangers and $A=$ mesh area of wire-net. The calculation gives a value approximately equal to $840 \mathrm{~kg}$. 


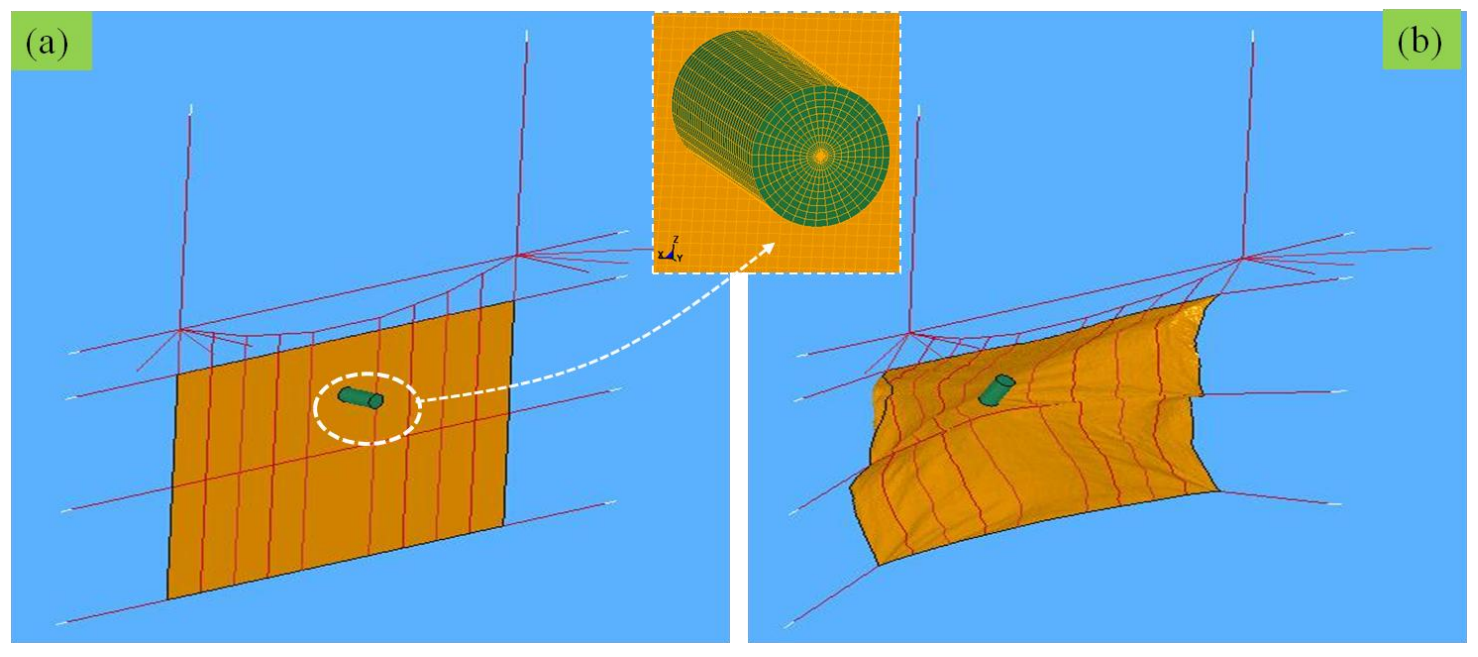

Fig. 7. FE model of the R-LPR. (a): undeformed state. (b): a deformed state.

The intensity of dead load (weight per unit horizontal length):

$\omega_{0}=\frac{W}{L}$

This gives a value of $0.56 \mathrm{kN} \mathrm{m}^{-1}$.

Vertical component of cable tension due to the dead load:

$V=\frac{\omega_{0} \times L}{2}$

And, the horizontal component:

$H=\frac{\omega_{0} \times L^{2}}{8 \times s}$

Thus, the resultant tension is given by:

$T=\sqrt{V^{2}+H^{2}}$

which computes the value of pretension in the sag-cable to be approximately $11 \mathrm{kN}$.

The appropriately meshed and fully calibrated FE model was then to be impacted with the cylinder (rockfall equivalent block) of 1-ton mass, length to diameter ratio of 2, with an initial (incident) velocity of $17.33 \mathrm{~m} \mathrm{~s}^{-1}$ (kinetic energy of $150 \mathrm{~kJ}$ ) at the location shown by the circle on the net area; following exactly what existed in the corresponding FM test situation. The block was modelled by Solid elements and assigned with the Rigid (MAT_020) material model. The reinforced concrete used to mould the block in the test was assumed to have the density of $2600 \mathrm{~kg} \mathrm{~m}^{-3}$ with an arbitrary Young's modulus of $35 \mathrm{GPa}$ and Poisson's ratio of 0.167 . The impact-contact algorithm Surface_To_Surface inbuilt in LSDYNA was used with block and net, respectively, as master and slave parts, and constant values of coefficients of friction equalling to 0.15 . The hourglass control (*HOURGLASS) was introduced in stiffness form $(\mathrm{IHQ}=4)$. Finally, the LSDYNA inbuilt explicit time history analysis was carried out to simulate the dynamic and nonlinear responses of the RLPR.

\subsection{Numerical results}

Figure 7 shows the FE model of R-LPR, both in the undeformed and deformed states. This model has 73894 nodes and 75906 elements in total, with 60000 Shells, 2946 Beams and 12960 Solids and the the average computation time of the model in an ordinary PC workstation is around a day. The dense meshing for Solid was adopted to take precaution for possible instability due to contact penetration following the suggestion by Hallquist (2006). This is fair because as the stresses and strains for Rigid material assigned to the Solids are not updated in the time history analysis and, hence, the densely meshed elements require no further computational costs. The structural responses corresponding to those measured in the FM, viz., the maximum cable tension, at location $\mathrm{M}$, the corresponding maximum UFD slip-displacement (slippage), and the maximum out-of-plane displacement of wire-net $\left(D_{\mathrm{m}}\right)$, just below the impact point, are shown in Fig. 8. The authors' sensitivity analyses (not detailed here for brevity) reveal the negligible effects of the parameters such as damping, hourglass, friction, etc. The overall results are in good agreement with the corresponding responses in the FM. Thus, it is assumed that the exercised NM is successfully and completely simulating the behaviour of the resilient cable-net-dissipator structural system of the R-LPR.

\section{Analytical modelling (AM)}

Since history, the full-scale physical modelling equivalent to the described FM has been dominating the overall research 


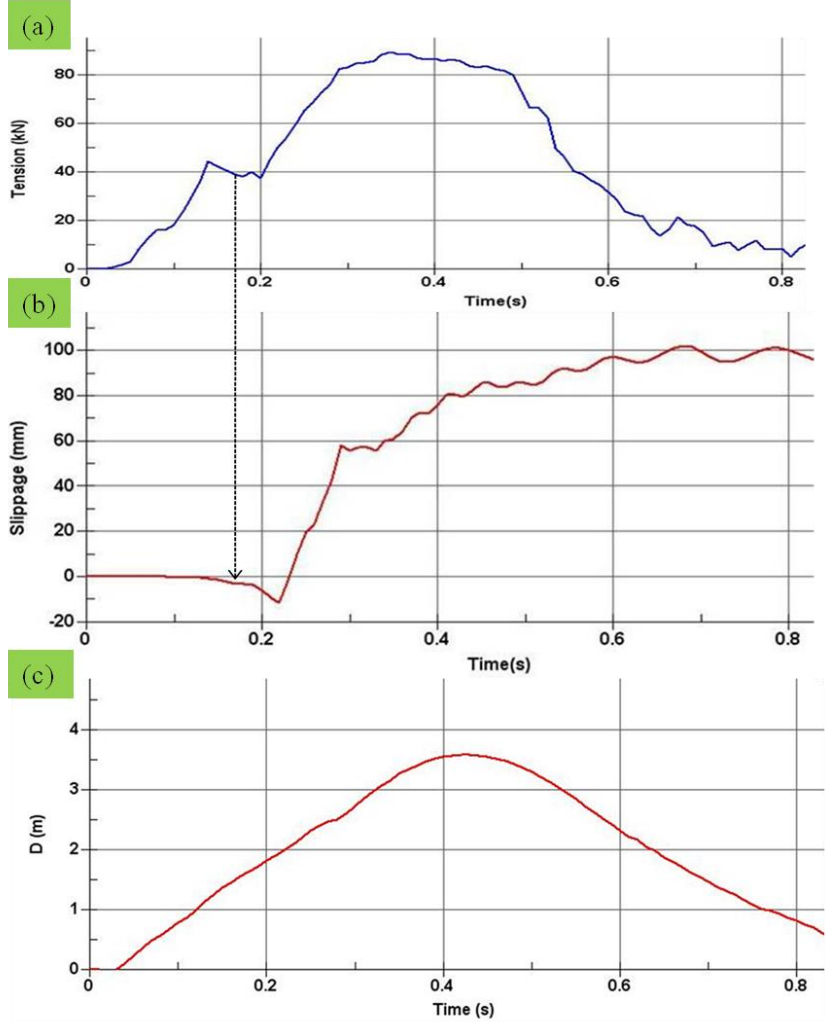

Fig. 8. Numerical simulation (NM) results. (a): maximum cable-tension, at location M. (b) Maximum UFD-slippage (slipdisplacement), at location M. (c) Maximum wire-net's out-of-plane displacement, just below the impact point. See also Fig. 3 for the corresponding FM results.

on rockfall protection, precisely the flexible (cable-net) protective systems. Over a decade or so, numerical modelling has also proved its importance either to aid or replace the full-scale tests, which normally incurs a large budget and mechanically less detailed and, therefore, sometimes limited to fully disclose the behaviour of the structure. The concept, approach and application of simple, analytical modelling are rare, except for a few recent contributions such as Schellenberg (2007), Cantarelli et al. (2008) and Miranda et al. (2010). As the first attempt, in the present work, the authors have preferred to propose the simplest possible analytical model that may equivalently simulate the global response, primarily the displacement response. It has already been identified that the displacement may be the most vital performance criteria for LPR under the assumption that the barrier components do not fail, and the typical practical situation to put the global displacement demand of the structure into priority has already been explained in Sect. 2.2.
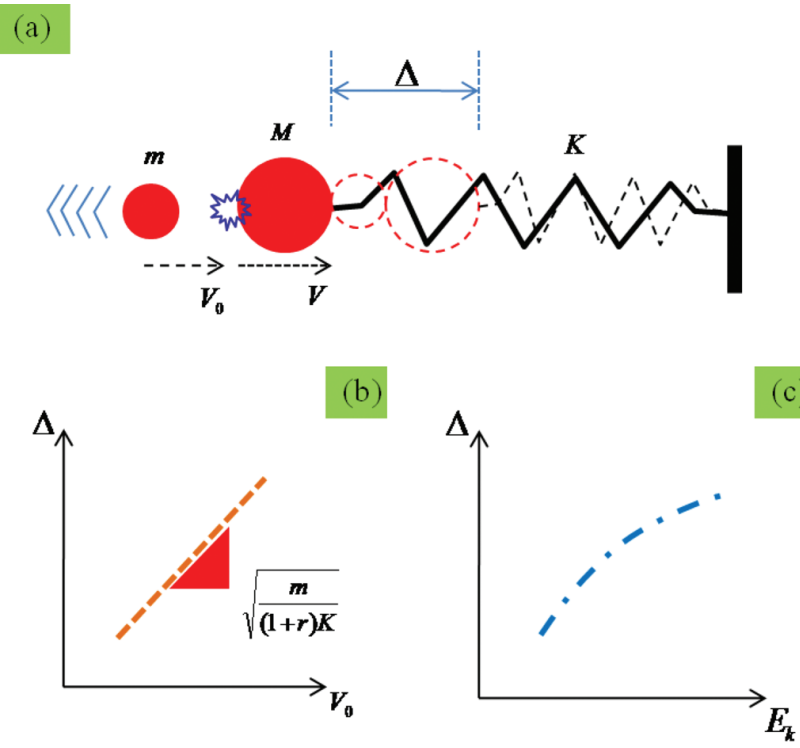

Fig. 9. Analytical modelling and formulation. (a): a simple lumped mass SDOF analytical model proposed for LPR structure. (b): the formulated linear relation between the structural displacement and the velocity of the block; the slope of the line is also shown. (c): the nonlinear (quadratic) relation between the structural displacement and the incident kinetic energy of the block.

\subsection{Model formulation}

The structure was assumed to be modelled by a lumpedmass, equivalently linearly elastic, single-degree-of-freedom (SDOF) system. And, the model's behaviour was assumed to be guided by the simple, first principles, of the conservation of linear momentum and the conservation of energy (Lam et al., 2010). The proposed model is shown in Fig. 9a. The equivalent lumped mass $M$ and the equivalent stiffness $K$ are the two important properties to be determined. The rock-block of certain mass, say $m$, impacts the SDOF model, thereby transferring the momentum and energy to the latter. It may be fair enough to assume that the momentum is fully transferred after the impact, but the observation that the impacting block moves together with the LPR cable-net system after impact reveals that the kinetic energy of the block is not fully transferred, and certain energy is lost in the impact. However, the remaining energy in the form of the kinetic energy of the coalesced block-structure just after impact should be equivalent to the energy absorbed by the structure - by the stiffness $K$ of the SDOF model - causing it to be deformed by $\Delta$. With this assumption, the two conservation principles were applied in combination for the formulation that could predict the displacement response of the SDOF model as postulated below. 


$$
\begin{gathered}
m \times V_{0}=(m+M) \times V \Rightarrow V=\frac{m}{m+M} \times V_{0} \\
\text { or, } V=\frac{V_{0}}{1+r} \text { with } r=\frac{M}{m}
\end{gathered}
$$

$$
\begin{aligned}
E_{k}= & \frac{1}{2} m \times V_{0}^{2}=\frac{1}{2}(m+M) \times V^{2}+\delta E \\
& \text { and, } \frac{1}{2}(m+M) \times V^{2}=\frac{1}{2} K \times \Delta^{2}
\end{aligned}
$$

Combining Eqs. (9) and (10), a displacement prediction equation is obtained as:

$\Delta=\sqrt{\frac{m}{(1+r) K}} \times V_{0} \Rightarrow \Delta \propto V_{0}(\propto$ to mean proportional $)$

or,

$\Delta=\sqrt{\frac{2 E_{k}}{(1+r) K}} \Rightarrow \Delta \propto \sqrt{E_{k}}, E_{k} \propto \Delta^{2}$

Equation (9) represents the conservation of linear momentum, while Eq. (11) the conservation of energy, where $V_{0}$ is the incident velocity, and $E_{k}$ the corresponding kinetic energy of the impacting block. $V$ is the velocity of the coalesced block-structure system immediately after the impact and $\delta E$ is the energy lost on impact. Clearly seen from Eqs. (11) and (12) is that the displacement is a linear function of the incident velocity of the impacting block and is a quadratic function with the corresponding energy which is shown schematically in Fig. 9b and c. Importantly, the slope (gradient) of the linear displacement-velocity line is given by:

$$
\text { Slope }=\sqrt{\frac{m}{(1+r) K}}
$$

\subsection{Model calibration}

The straight forward calculations of the equivalent mass and the equivalent stiffness of the complex system like LPR are virtually impossible. Thus, they should be determined by back calculation by either of the earlier modelling, that is, the FM or the NM. Now, there is already a verified numerical model, so it may be readily utilised. Equations (9) and (13) of the analytical formulation may be used to determine the properties of the proposed model. For the latter, at least three numbers of numerical parametric analyses were deemed necessary. Here, a different idealized block was used. In fact, the analyses could have been continued with the same cylindrical block used in the FM or the NM. However, it was utilised up to numerically simulating the R-LPR as observed in the FM and to verify the NM adopted by the authors. For the subsequent parametric analyses of the R-LPR, a more rational rockfall looking ETAG027-like octagonal shape (EOTA, 2008; Peila and Ronco, 2009) was used. The decision was

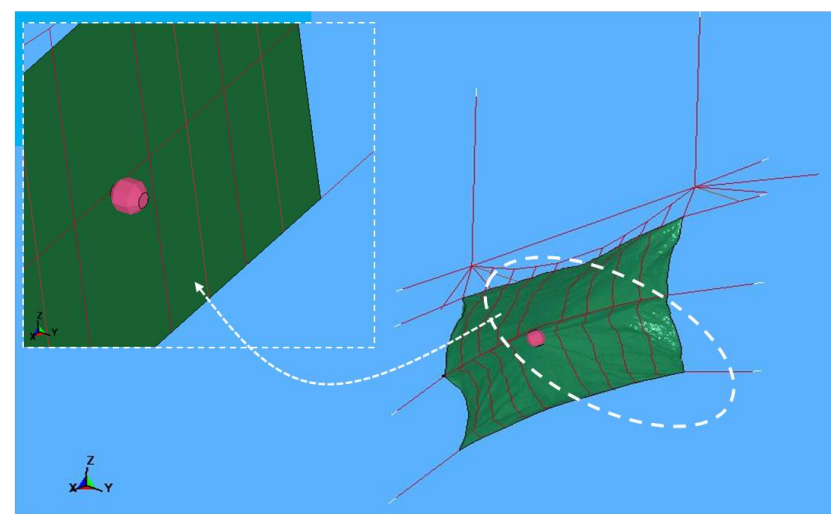

Fig. 10. The verified FE model of the R-LPR now impacted by the ETAG027-like block.

also dictated by the increasing global acceptance of the European codes. Figure 10 shows the deformed FE model of the structure impacted by the ETAG027-like octagonal block. It is again reminded that deformation (displacement response) is more important than the sufficiently safer force (stress states) for the performance of a typical LPR design, having identified from full-scale modelling.

Figure 11 represents a typical "Global Y-velocity" response time history of the cylindrical block of 1-ton mass impacting the studied R-LPR at the incident velocity of $17.33 \mathrm{~m} \mathrm{~s}^{-1}$. From this figure, the velocity immediately after the impact, when the cable-net restraining system and the block move together (inelastic impact), is obtained to be $7.66 \mathrm{~m} \mathrm{~s}^{-1}$. Substituting the two velocity values in Eq. (9) gives the equivalent mass $M$ to be $1262 \mathrm{~kg}$. Thus, one important parameter is determined.

Figure 12, on the other hand, shows the plot of displacement response values at different velocities and impact energies of the ETAG027-like octagonal block having the mass of $778 \mathrm{~kg}$, confirmed after modelling, hitting the same verified numerical model. For the sake of effective graphical presentation, with the two related curves on the same chart, the response displacement was deliberately placed on the horizontal axis despite that it is a dependent variable. Likewise, the slope defined by the expression in Eq. (13) was made equal to the inverse of the value calculated from the velocitydisplacement plot of Fig. 12. The corresponding slope (displacement vs. velocity) comes out to be $68.45 \times 10^{-3}$. Substituting this value into the expression of slope, Eq. (13), with $m=778 \mathrm{~kg}$ and $r=(1262 / 778)=1.62$, calculates the value of the equivalent stiffness $K$ to be $63366 \mathrm{~N} \mathrm{~m}^{-1}$. Thus, another important variable of the proposed SDOF model of the R-LPR could also be determined. Interestingly, the equation of the correlation (trend-line) between the displacement response and velocity from Fig. 12, also rearranged in Eq. (14), reveals that, only the basic form of Eq. (11) obtained by applying the principles of momentum-energy transfer into the highly simplified elastic, pseudo-static and lumped-mass, 


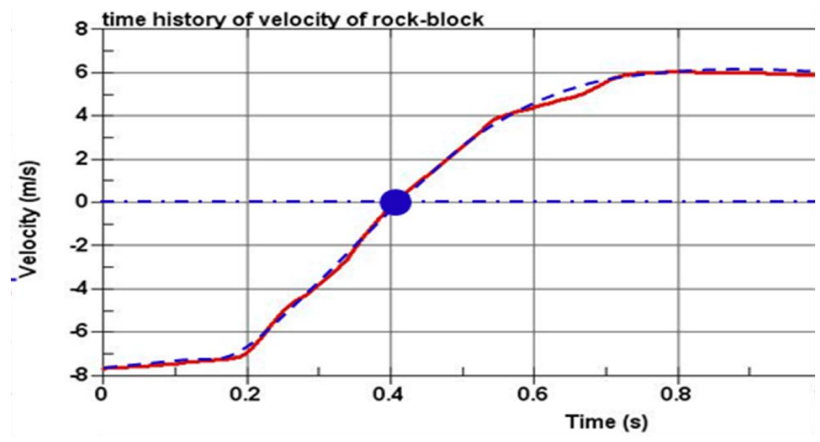

Fig. 11. A typical time history response of the Global Y-velocity including initial coalesced motion - of the cylindrical block of 1 ton mass and the incident velocity of $17.33 \mathrm{~m} \mathrm{~s}^{-1}$.

SDOF modelling to represent the highly complex system of LPR is not sufficient and needs modification. The necessary modification may be attributed to the factors such as geometric nonlinearity, dynamic loading, higher mode deformations, etc. Nonetheless, the simple analytical model may be readily retained as the basic variable constituting component of the correlation. The global displacement of the structure is, thus, conveniently predicted after a modification that compares with Eq. (14). The final form of the displacement prediction correlation for the studied LPR configuration modelled with the described very simple SDOF modelling is, therefore, as given in Eq. (15). A more general form of the correlation is shown in Eq. (16).

$D_{\mathrm{m}}=0.06845 V_{0}+2.135$

$\Delta=\frac{m V_{0}}{\sqrt{63366(m+1262)}}+2.135$

$\Delta=\sqrt{\frac{m}{\left(1+\frac{M}{m}\right) K}} V_{0}+2.135$

Therefore, via back-calculations using the verified numerical modelling (second tier), the calibration and necessary modification over the simple analytical formulation, capable of predicting the global displacement response of the complex structure could be successfully accomplished in the third-tier modelling. The correlation is the function of the structure's equivalent global mass and equivalent global stiffness, and the rock-block's mass and velocity. Application of the proposed correlation, for example, to a block of mass of $1000 \mathrm{~kg}$ impacting at the velocity of $17.33 \mathrm{~m} \mathrm{~s}^{-1}$ (as equivalent to the case of the cylindrical block described in the numerical modelling section), predicts the displacement response to be $3.58 \mathrm{~m}$. This indeed compares very well with that obtained directly from the corresponding rigorous numerical simulation. However, it may be noted that the correlation, having devised by considering a limited range of impact energy basically by varying the velocity of impact, may not be extrapolated to either much lower or much higher energy (say, roughly as high as $500 \mathrm{~kJ}$ ) since other factors such

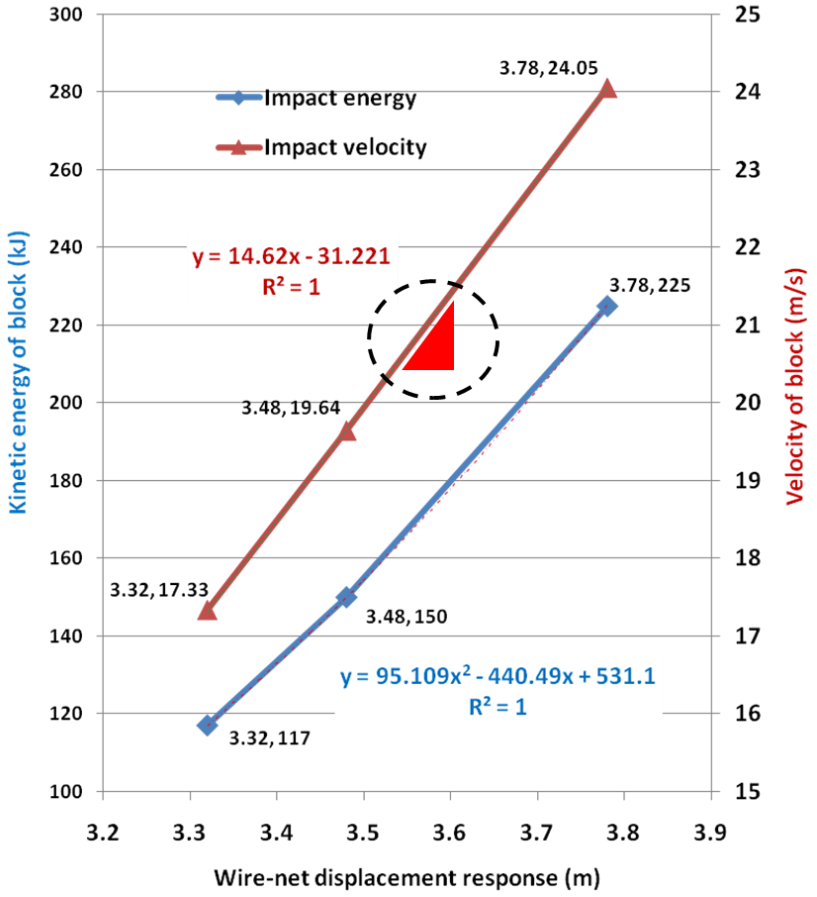

Fig. 12. Displacement response of R-LPR at various incident velocities and the corresponding kinetic energies of the impacting block by using the model shown in Fig. 10. The slope to be determined is marked by a circle.

as the localized contact-impact effects may potentially introduce nonlinear functions.

\subsection{Further application of the model}

The lumped-mass SDOF equivalent structural model is very convenient to handle and visualize, again to be emphasized, for the global structural displacement performance (physically corresponding with the out-of-plane displacement of the real LPR). Having known the equivalent mass and the equivalent stiffness, one may utilise the model for various individual aspects. For example, if someone is interested in having the insight into the structure through its natural frequency or period of vibration, it may be computed from Eq. (17) given below.

$T_{n}=2 \pi \sqrt{\frac{M}{K}}$

Or, in coalesced vibration,

$T_{n}=2 \pi \sqrt{\frac{m+M}{K}}$

Equation (18), for instance, with the block of mass of 1 ton, for instance, gives a value equal to $1.19 \mathrm{~s}$.

If someone else, on the other hand is interested in dealing with the structural responses by the model with respect to 
the various parameters such as the varying impact energy or velocity of the block or the ratio of the mass of the LPR structure to that of the impacting block at the constant impact energy - the trend "not captured by the contemporary codified calculation methods for impact actions" (Yang et al., 2011), the simple correlation derived in Eq. (16) may help. Clearly seen is that the wire-net displacement may be reduced by simply increasing the mass of its cable-net resilient system (density, for instance), not necessarily the stiffness contributing properties such as the thickness. Again, with this simple model, the different displacement responses of an LPR for "heavy" (larger mass, smaller velocity) and "light" (smaller mass, larger velocity) falling rock-boulders that might have carried the same kinetic energy may be clearly understood. A detailed exploration on the characterisation of rockfall impact loading onto the structure may be found in a separate companion contribution by the authors in future.

\section{Conclusions and recommendations}

Commenced with a brief reporting of the development of a new configuration of rockfall protective cable-net structure (flexible barrier) in Japan, known as Long-span Pocket-type Rock-net (LPR), the paper focussed on the authors' primary objective of conducting a three-tier modelling of the newly developed protective system. Their methodologies and results were presented separately and briefly. A 15-m span structure with designated design impact energy resistant capacity of $150 \mathrm{~kJ}$ was taken as the reference case (R-LPR) throughout the study.

For the time being, the LPRs of span from $10 \mathrm{~m}$ to $30 \mathrm{~m}$ are proposed for low-to-medium impact energy scenarios (say below $500 \mathrm{~kJ}$ of design impact energy resistant capacity), at the toe of hill or nearby the infrastructure to be protected, or more precisely when there is a limited space between the road carriageway and the hill-slope. In Japan, before the introduction of LPR, either short-span ( 3 or $5 \mathrm{~m}$ ) pocket-type rock-net or rock-sheds (reinforced concrete galleries) were prevalent in the described sites. The former not only had lower capacity (thereby requiring installation in cascade uphill) and incurred larger cost for more materials as well as installation, but also performed weakly by having their posts repeatedly damaged by the direct impact of the falling rockboulder. The latter was not only difficult to construct and had very high dead-load, but was again an expensive alternative, especially because they have high-to-very-high capacity range which is never utilised in the low-to-medium rockfall hazard sites. With the advent of LPR system, the disadvantages of the prevailing solutions have been overcome and in either case, it has ecological benefits as well. The system was first introduced in real field at various locations of KureiSuzaki Line road, along Pacific Ocean, in Kochi Prefecture of Japan, and the subsequent performance has been found encouraging. These structures are now finding an increased application within Japan and similar systems are expected to be developed in future in other parts of the world too. In fact, assuming the construction materials are fairly available, rockfall protective earthen embankments (or geo-cells) widely developed, tested and used in various parts of the world can be as effective and economic as flexible barriers even in the low-to-medium rockfall hazard sites. However, they generally require a larger space, and the design like LPR can be a good alternative in such a constraint.

In the first-tier modelling of the considered R-LPR structure, full-scale (experimental) modelling was discussed. The structure performed pretty well in the test. Owing to the sufficiently safer stress state in cable too, the displacementbased performance criteria may be emphasized in the analysis and design of an LPR structure, due to the fact that the targeted sites of LPR application generally have very limited set-back. Thus, the authors tend to recommend that an extended investigation be made in future on the various possibilities to control the out-of-plane displacement of wire-net in LPR but still limiting the stresses even if higher strength steel is not utilised for cables. One of the solutions may be increasing the weight of the structure as suggested by the simple analytical formulation explained in the later section of this work (Sect. 4.3). Moreover, it is identified that the evaluation, enhancement and optimization of the existing Ubolt-type Friction-brake energy dissipating Devices (UFDs) integrated into an LPR system is worth trying in future. However, for such various intended explorations that shall be requiring a number of parametric analyses of the structure, the method of full-scale modelling is not viable and may not be sufficient as well due to their limitations in instrumentation. This justifies the need of searching for more easily replicable, as simplified and convenient as practicable and overall, the object-oriented and cheapest alternative.

In the second-tier modelling, the R-LPR structure was modelled with Finite Elements in the available numerical tool of LS-DYNA. A simplified modelling was adopted, wherein the main impact resilient cable-net-dissipator system was kept in the limelight but again following an equivalent modelling concept for the wire-net and the dissipator. The former was modelled by the Shell and the latter by the Truss elements. Their constitutive properties were modelled and calibrated by appropriate experiments conducted during the past full-scale test verification and/or demonstration campaign leading to the development of the LPR system. The developed numerical model excellently simulated the full-scale modelling results.

In the third-tier modelling, the complex design of the same LPR was assumed to be modelled analytically via the simplest possible, equivalently linear and elastic, lumped-mass, single-degree-of-freedom (SDOF) system, primarily capable of predicting the displacement response - the possibly most vital response parameter for the LPR analysis and design, as discovered from the full-scale modelling. The behaviour of the model was formulated starting from scratch and applying 
the first principles of the conservation of linear momentum and energy. The equivalent properties of the model were determined by back-calculations of the results of analyses on the verified numerical model, which also suggested the modification in the basic form of the displacement equation - thereby enabling the prediction of the complex nonlinear and dynamic displacement response of the R-LPR-like structure. Being aware of the much developed and internationally accepted European guidelines for rockfall protection, the EOTA (2008) recommended block shape was modelled for the subsequent parametric analyses. The proposed analytical model, despite being the simplest of its kind, which could be developed for a selected set of designs based on experimental and/or numerical simulations, can be very helpful to a design engineer to conduct various simple computational parametric analyses for the better understanding of the behaviour of the system. The model, for instance, may be utilised for the investigation toward enhancing the effectiveness of an LPR structure by controlling its global displacement response, or even for the preliminary design works in a practical range of designated impact energy - neither going too high nor too low. The detailed application of the proposed numerical and analytical modelling (displacement predictive correlation) shall be covered in a separate companion paper.

In a nutshell, the authors successfully materialized the set objective of three-tier modelling of a newly developed rockfall protective system. The approach and rationale of the modelling contained in this work may be useful also while dealing with other similar development and/or analyses of a protective system in future. It is, however, to be highlighted here that if such a protective system is developed in Europe, for the barrier to be executed in the field, the existing practice would require to pass the full-scale test certification based on the guideline ETAG027 recently endorsed by EOTA following the existing Swiss guideline endorsed by SAEFL and WSL (Gerber, 2001). Even in such situations, the proposed simplified numerical and analytical modelling would become very helpful for conducting parametric analyses for preliminary design, system enhancement and optimization before finally entering into full-scale modelling for test-certification.

Acknowledgements. The authors thank Daiichi Consultants Co., Kochi, Japan (particularly the chairperson, T. Ushiro), Nihon Protect Co., Matsuyama, Japan and Besafe Consultants Co., Niigata, Japan for the test results used in this paper. The first author gratefully acknowledges N. T. K. Lam, University of Melbourne, Australia, A. Volkwein, WSL, Switzerland, and J. P. Ghimire, Commonwealth Engineers Co. Ltd., Tokyo for their kind email responses, comments and helpful suggestions at times. Sincere thanks are also due to two anonymous referees who very minutely and beautifully commented over the submitted manuscript, thereby helping to improve it to the present stage. Last but not least, the first author is thankful to his wife Sweta Acharya (Dhakal) for her assistance throughout.

Edited by: T. Glade

Reviewed by: two anonymous referees

\section{References}

Arndt, B., Ortiz, T., and Turner, K.: Colorado's full-scale field testing of rockfall attenuator systems, Transportation Research Circular E-C141, Transportation Research Board, 2009.

Azzoni A., Barbera, G. L., and Zaninetti, A.: Analysis and prediction of rockfalls using a mathematical model, Int. J. Rock Mech. Min. Sci. Geomech. Abstr., 32, 709-724, 1995.

Badger, T. C., Duffy, J. D., Sassudelli, F., Ingraham, P. C., Perreault, P., Muhunthan, B., Radhakrishnan, H., Bursi, O. S., Molinari, M., and Castelli, E.: Hybrid barrier systems for rockfall protection, in: Proc. of the Interdisciplinary Workshop on Rockfall Protection, edited by: Volkwein, A., Morschach, Switzerland, 10-12, 2008.

Badger, T. C., Dobrev, B., Anderson, M., Radhakrishnan, H., and Muhunthan, B.: Structural design of a hybrid drapery system, in: Book of abstract, Interdisciplinary Workshop on Rockfall Protection, edited by: Molk, M., Melzner, S., Sausgruber, T., and Tartarotti, T., 3 pp., 2011.

Bertolo, P., Oggeri, C., and Peila, D.: Full-scale testing of draped mesh for rock fall protection, Can. Geotech. J., 46, 306-317, 2009.

Besafe: E-fence experimental report, Besafe Co. Ltd., Niigata, Japan, 2006 (in Japanese).

Boetticher, A. V., Glover, J., Volkwein, A., and Denk, M.: Modelling flexible wire netting applied to rock fall attenuating systems, in: Book of abstract, Interdisciplinary Workshop on Rockfall Protection, edited by: Molk, M., Melzner, S., Sausgruber, T., and Tartarotti, T., 71-72, 2011.

Bunce, C. M., Crude, D. M., and Morgenstern, N. R.: Assessment of the hazard from rockfall on a highway, Can. Geotech. J., 34, 344-356, 1997.

Cantarelli, G., Giani, G. P., Gottardi, G., and Govoni, L.: Modelling rockfall protection fences, Web Proc. Of First World Landslide Forum, Tokyo, Japan, 662-667, 2008.

Castro-Fresno, D., Diaz J. J. d. C., Lopez, L. A., and Nieto, P. J. G.: Evaluation of the resistant capacity of cable nets using the finite element method and experimental validation, Eng. Geol., 100, 1-10, 2008.

Cazzani, A., Mongiovi, L., and Frenez, T.: Dynamic finite element analysis of interceptive devices for falling rocks, Int. J. Rock Mech., 39, 303-321, 2002.

Crosta, G. B. and Agliardi, F.: A methodology for physically based rockfall hazard assessment, Nat. Hazards Earth Syst. Sci., 3, 407-422, doi:10.5194/nhess-3-407-2003, 2003.

Descoeudres, F., Stoffel, S. M., Boll, A., Gerber, W., and Labiouse, V.: Chapter 4, Rockfalls, in: Coping study on disaster resilient infrastructure, commissioned by the secretariat for the international decade for natural disaster reduction for the INDR programme forum "Parterships for a safer world in the 21st century", edited by: Minor, H.-E., United Nations, 37-46, 1999.

Dhakal, S., Bhandary, N. P., Yatabe, R., and Kinoshita, N.: Finite element modelling and parametric analyses of a Long-span Pockettype rockfall interceptive cable-net structure, Proc. of Second World Landslide Forum, Rome, Italy, 3-7 Oct., 2011a.

Dhakal, S., Bhandary, N. P., Yatabe, R., and Kinoshita, N.: Numerical investigation of the effects of idealized rock-block shapes and impact points on the performance of Long-span Pocket-type Rock-net, Proc. of 46th Japan National Conference on Geotechnical Engineering, CD-ROM, July 5-7, Kobe, Japan, 1885-1886, 
2011b.

Dhakal, S., Bhandary, N. P., Yatabe, R., Pradhan, P. L., and Tiwari, R. C.: Finite element modeling and decoupled seismic stability analysis of a zoned rockfill dam designed by traditional empirical methods, J. Inst. Eng., 8, 71-92, 2011c.

Dorren, L. K. A. and Berger, F.: Stem breakage of trees and energy dissipation during rockfall impact, Tree Physiol., 26, 63-71, 2005

Eliassen, T. D.: Evaluation of hybrid rockfall barrier/drape system, Initial Report-Experimental Features, Project No. 2011-1, Work Plan 2008-1, Ste of Vermont, Agency of Transportation, Materials and Research Section, 9 pp., 2011.

EOTA: Guideline for European Technical Approval of falling rock protection kits, European Organization for Technical Approvals, Brussels, 53 pp., 2008.

Evans, S. G. and Hungr, O.: The assessment of rockfall hazard at the base of talus slopes, Can. Geotech. J., 30, 620-636, 1993.

Fukazawa, J., Sonoda, Y., and Tamai, H.: A fundamental study on the discretization degree and calculation accuracy of impact analysis using SPH method, J. Struct. Eng., 56A, 1169-1176, 2010 (in Japanese).

Fell, R., Corominas, J., Bonnard, C., Cascini, L., Leroi, E., and Savage, W. Z. on behalf of the JTC-1 Joint Technical Committee on Landslides and Engineered Slopes: Guidelines for landslide susceptibility, hazard and risk zoning for land-use planning, Eng. Geol., 102, 85-98, 2008a.

Fell, R., Corominas, J., Bonnard, C., Cascini, L., Leroi, E., and Savage, W. Z. on behalf of the JTC-1 Joint Technical Committee on Landslides and Engineered Slopes: Guidelines for landslide susceptibility, hazard and risk zoning for land-use planning, (Commentary), Eng. Geol., 102, 99-111, 2008b.

Gerber, W.: Guideline for the approval of rockfall protection kits, Swiss Agency for the Environment, Forests and Landscape (SAEFL), and Swiss Federal Research Institute (WSL), Berne, Switzerland, 41 pp., 2001 (Amendment, 2006).

Giani, G. P.: Rock slope stability analysis, Balkema, Rotterdam, Netherlands, 1992.

Giani, G. P., Giacomini, A., Migliazza, M., and Segalini, A.: Experimental and theoretical studies to improve rock fall analysis and protection work design, Rock Mech. Rock Engng., 37, 369-389, 2004.

Grassl, H., Volkwein A., Anderheggen, E., and Ammann, W. J.: Steel-net rockfall protection, Proc. of Seventh International Conference on Structures under Shock and Impact, Montreal, Canada, 143-153, 2002.

Guzzeti, F., Crosta G., Detti, R., and Agliardi, F.: STONE: a computer programme for the three dimensional simulation of rockfalls, Comput. Geosci., 28, 1079-1093, 2002.

Guzzetti, F., Reichenbach, P., and Wieczorek, G. F.: Rockfall hazard and risk assessment in the Yosemite Valley, California, USA, Nat. Hazards Earth Syst. Sci., 3, 491-503, doi:10.5194/nhess-3491-2003, 2003.

Gottardi, G. and Govoni, L.: Full-scale modelling of falling rock protection barriers, Rock Mech. Rock Eng., 43, 261-274, 2010.

Hallquist, J. O.: LS-DYNA theory manual, Livermore Software Technology Corporation (LSTC), 2006.

Japan Road Association: Rockfall Mitigation Handbook, Maruzen, 2000 (in Japanese).

Kinoshita, N.: Development of Long-span Pocket-type Rock-net,
Proc. of Annual Meeting of Ministry of Land, Infrastructure, Transport and Tourism, Shikoku Regional Development Bureau, Japan, I1, 1-4, 2009.

Lam, N. T. K., Tsang, H. H., and Gad, E. F.: Simulations of response to low velocity impact by spreadsheet, Int. J. Struct. Stab. Dynam., 10, 1-17, 2010.

LSTC: LS-DYNA Keyword User's Manual, Vol. I-II, V971, Livermore Software Technology Corporation (LSTC), 2007.

Maegawa, K.: Weight impact tests on a flexible polyethylene net rock fence, Proc. of the 3rd International Conference on Protection of Structures against Hazards, 43-50, 2006.

Masuya, H., Amanuma, K., Nishikawa, Y., and Tsuji, T.: Basic rockfall simulation with consideration of vegetation and application to protection measure, Nat. Hazards Earth Syst. Sci., 9, 1835-1843, doi:10.5194/nhess-9-1835-2009, 2009.

Miranda, S. d., Gentilini C., Gottardi, G., Govoni, L., and Ubertini, F.: A simple model to simulate the full-scale behaviour of falling rock protection barriers, in: Physical Modelling in Geotechnics, edited by: Springman, S. M., Laue, J., and Seward, L. J., London, 1247-1252, 2010.

Muhunthan, B., Shu, S., Sasiharan, N., Hattamleh, O. A., Badger, T. C., Lowell, S., M., and Duffy, J. D.: Analysis and design of wire mesh/cable net slope protection, Final Research Report. Washington State Transportation Commission - Department of Transportation, US Department of Transportation - Federal Highway Administration, 2005.

Muraishi, H., Samizo, M., and Sugiyama, T.: Development of a flexible low-energy rockfall protective fence, QR of RTRI, 46, 161-166, 2005.

Nicot, F., Cambou, B., and Mazzoleni, G.: Design of rockfall restraining nets from a discrete element modelling, Rock Mech. Rock. Eng., 34, 98-118, 2001.

Peila, D.: Chapter 12, Ground reinforced embankments for rockfall protection - From real scale tests to numerical modelling, in: Rockfall Engineering, edited by: Lambert, S. and Nicot, F., John Wiley \& Sons, New York, ISTE Ltd., London, ISBN 9781-84821-256-5, 2011.

Peila, D. and Guardini, C.: Use of the event tree to assess the risk reduction obtained from rockfall protection devices, Nat. Hazards Earth Syst. Sci., 8, 1441-1450, doi:10.5194/nhess-8-1441-2008, 2008.

Peila, D. and Ronco, C.: Technical Note: Design of rockfall net fences and the new ETAG 027 European guideline, Nat. Hazards Earth Syst. Sci., 9, 1291-1298, doi:10.5194/nhess-9-1291-2009, 2009.

Peila, D., Pelizza, S., and Sassudelli, F.: Evaluation of behaviour of rockfall restraining nets by full scale tests, Rock Mech. Rock Eng., 31, 1-24, 1998.

Reddy, J. N.: An introduction to nonlinear finite element analysis, Oxford University Press, New York, 2004.

Sasiharan, N., Muhunthan, B., Badger, T. C., Shu, S., and Carradine, D. M.: Numerical analysis of the performance of wire mesh and cable net rockfall protection systems, Eng. Geol., 88, 121132, 2006.

Schellenberg, K.: On the design of rockfall protection galleries, $\mathrm{PhD}$ Thesis, Institute of Structural Engineering, Swiss Federal Institute of Technology, Zurich, Switzerland, 2007.

Smith, D. D. and Duffy, J. D.: Field tests and evaluation of rockfall restraining nets. CA/TL-90/05, Final Report, California Depart- 
ment of Transportation, Office of Transportation, Materials and Research, Sacramento, CA, USA, 1990.

Tajima, T., Maegawa, K., Iwasaki, M., Shinohara, K., and Kawakami, K.: Evaluation of pocket-type rock net by full-scale tests, Proc. of 33rd IABSE Symposium, Bangkok, Thailand, available at: http://133.28.114.77/maegawa/ IABSE-Symposium2009-212_07_01.pdf, 8 pp., 2009.

Ushiro, T., Masahiro, K., Shinohara, S., and Kinoshita, K.: An experimental study related to rock fall movement mechanism, Doboku Gakkai Ronbunshu F, 62, 377-386, 2006 (in Japanese).

Vogel, T., Labiouse, V., and Masuya, H.: Rockfall protection as an integral task, Struct. Eng. Int., 19, 304-312, 2009.

Volkwein, A.: Numerical simulation of flexible rockfall protection systems, Diss. ETH, Nr. 15641, PhD thesis, ETH, Zurich, available at: http://e-collection.library.ethz.ch/eserv/eth:27491/ eth-27491-02.pdf, 134 pp., 2004 (in German).
Volkwein, A.: Numerical simulation of flexible rockfall protection systems. Proc. of The ASCE International Conference on Computing in Civil Engineering, Cancun, Mexico, doi:10.1061/40794(179)122, 2005.

Volkwein, A., Roth, A., Gerber, W., and Vogel, A.: Flexible rockfall barriers subjected to extreme loads, Struct. Eng. Int., 19, 327332, 2009.

Yang, Y., Lam, N. T. K., and Zhang, L.: Evaluation of simplified methods of estimating beam responses to impact, Int. J. Struct. Stab. Dynam., accepted, 2011.

Yoshida, H.: Recent experimental studies on rockfall control in Japan, in: Proc. of the Joint Japan-Swiss Scientific Seminar on Impact Load by Rock Falls and Design of Protection Structures, edited by: Masuya, H. and Labiouse, V., Kanazawa, Japan, 69$78,1999$. 